\title{
Victimization and PTSD in an Indian youth sample from Pune City
}

\author{
Ditte J. Rasmussen, Sidsel Karsberg, Karen-Inge Karstoft, Ask Elklit*
}

Danish National Centre of Psychotraumatology, University of Southern Denmark, Odense, Denmark

Email: * $\underline{\text { aelklit@health.sdu.dk }}$

Received 10 December 2012; revised 17 January 2013; accepted 24 January 2013

\begin{abstract}
Background: Indian adolescents are presumably exposed to a range of potentially traumatizing and negative life events. However, the knowledge on this area is relatively sparse. The present study aims to investigate the prevalence of exposure to potentially traumatizing and negative life events and the occurrence of Posttraumatic Stress Disorder (PTSD) among a specific sample of Indian adolescents. Method: A sample of 411 Indian 9th graders ( $M=14.15$ years), from two private schools in Pune City answered a questionnaire about 1) socio-demographical background and 2) the direct or indirect exposure to 20 specific, potentially traumatizing and negative life events. Also, they filled out Part IV of the Harvard Trauma Questionnaire (HTQ-IV) to assess their level of PTSD-symptoms. Results: $70 \%$ of the females and $85 \%$ of the males had been exposed to or witnessed at least one traumatizing or negative life event. The mean number of experienced events was 2.5. The most common events were: death of someone close, traffic accidents, serious illness, witnessing the injury or killing of others, and coming close to being injured or killed. The prevalence of PTSD was $10 \%$. Males reported higher direct as well as indirect exposure than females to all events, while no significant gender difference was found in the prevalence of PTSD. Living in a single-parent household meant increased risk of developing PTSD. Conclusion: Exposure to potentially traumatizing events was comparable to that seen in similar studies in Western European youth samples. Prevalence of PTSD was also in the same range. This may be attributable to a number of protective factors associated with the specific sample. Males were exposed to more potentially traumatizing events than females, but contradictory to most other studies, no gender difference in prevalence of PTSD was seen. These differences in comparison to earlier studies might reflect cultural and national circum-
\end{abstract}

\footnotetext{
${ }^{*}$ Corresponding author.
}

stances that distinguish this Indian sample from Western European countries previously investigated.

Keywords: Adolescents; Posttraumatic Stress Disorder; Traumatic Events; Negative Life Events; India

\section{BACKGROUND}

The risk for trauma exposure seems to peak in adolescence [1]. In recent years, a growing number of studies have examined the impact of traumatic and negative life events on children and adolescents. These studies indicate that this group is at risk of developing Post Traumatic Stress Disorder (PTSD) and other behavioral, psychological, emotional, and neurobiological problems after a traumatizing experience $[2,3]$.

During the last decade, a number of epidemiological studies of PTSD among adolescents based on European national probability samples have been published. Still, probability samples among adolescents are rare compared to the number of convenience samples focusing on specific single events such as road traffic accidents [4], assaults [5], sexual abuse [6], natural disasters [7], and war [8]. Hence, the knowledge on general trauma exposure and PTSD prevalence among adolescents is relatively sparse.

In a longitudinal study of 384 US adolescents aged 18, Giaconia and colleagues [9] found that $43 \%$ of the total sample had experienced at least one DSM-III-R trauma, and that $6.3 \%$ met the criteria for PTSD. Joseph, Mynard $\&$ Mayhall [10] focused on less severe and more common negative life events, and in a community based study of 427 English adolescents (11 - 16 years) they found that $84 \%$ had experienced at least one negative life event. Costello and colleagues [11] also studied a broad range of potentially traumatic events in a general population study among 1420 children and adolescents (aged 9 - 16) in North Carolina. Approximately $25 \%$ of this sample had by the age of 16 experienced a high magnitude event (e.g. death of a loved one, natural disaster, abuse etc.; DSM-III-R extreme stressors), and $6 \%$ had experi- 
enced a low magnitude event (school transition, pregnancy, parental divorce etc.) within 3 months prior to the study.

In six studies of traumatic events and lifetime PTSD in national probability or total youth samples [12-17], prevalence of traumatic events and PTSD has been estimated for adolescents in Denmark, Iceland, Lithuania, the Faroe Islands, Israel and Kenya. The exposure to at least one potentially traumatizing event in these studies varied from $74 \%$ - 94\% for females and 78\% - 89\% for males. Prevalence rates of PTSD in these studies varied from $6.1 \%$ - 20\%, and they all showed that the female risk for PTSD after a traumatizing event was around twice the risk of males. By contrast to the above mentioned studies, Meltzer et al. [18] found a much lower prevalence of PTSD $(0.4 \%)$ in a British National Survey of more than 10,000 children and adolescents. However, in addition to methodological differences, this much lower number reflects a point prevalence estimate whereas the other reviewed studies report lifetime prevalence. In line with the abovementioned studies, this study also found that twice as many females as males met the criteria for clinical PTSD.

Observed variances in prevalence of exposure and PTSD may be due to differences in methodology as well as differences in demographic and culturally related variables. Despite the great variances in PTSD prevalence, the reviewed studies all show that many adolescents around the world do experience a considerable amount of potentially traumatizing events. Furthermore, the studies indicate that these experiences may lead to PTSD or other trauma related symptoms [2,3].

Across studies, certain factors seem to influence the development of PTSD. Giaconia et al. emphasize that family environment has great influence on PTSD development [9]. Ditlevsen and Elklit [19] stress that demographic factors such as age and gender can be moderators of the impact of victimization, and other factors such as living with both parents might have a moderating function as well. Several studies suggest that female gender, living in a single parent household, and having experienced multiple traumatic events increases the risk of PTSD [12,20].

\section{The Indian Perspective and the Present Study}

Nineteen percent of the world's child population lives in India; one third of the country's population $(\approx 440$ million $)$ are below 18 years of age. A report from the Indian Ministry of Women and Child Development [21] on child abuse among 12,447 children (ages 5 - 14) and 2324 adolescents (ages 15 - 18) has examined physical, sexual, and emotional abuse. Two out of three children report physical abuse; half the children report having faced one or more forms of sexual abuse, and half the children report emotional abuse. In spite of certain methodological limitations, the report sheds light on an otherwise tabooed subject and the high numbers indicate that an enormous group of children and adolescents are exposed to potentially traumatizing events and life conditions.

India in general is marked by enormous poverty, an ineffective healthcare system, regular terror attacks (e.g. Twin blast in Mumbai in 2005, Delhi bomb blasts 2008, Mumbai terror 2008 etc.), riots [22], and natural disasters (e.g. earthquake in Gujarat in 2001, tsunami in Tamil Nadu in 2004, floods in Bihar 2008 etc.). These conditions can be assumed to increase the risk of exposure to potentially traumatizing events. However, only few studies on PTSD have been conducted in India, and these are mostly about specific trauma events like vehicle accidents [23], intimate partner violence [24], and natural disasters [25]. As such, general knowledge on potentially traumatizing events and the specific impact on adolescents is lacking.

The present study was designed to provide epidemiological information about exposure to traumatic events and negative life events, and the prevalence of PTSD among Indian ninth graders. The study replicates previous similar studies of the same age groups and is therefore suitable for making cross-national comparisons.

In accordance with earlier studies on PTSD prevalence, a gender difference was expected with females fulfilling the criteria for PTSD significantly more often than males. General population studies find that even though males are more likely to experience traumatic life events, females develop PTSD approximately twice as often as males $[12,13,15,19]$. Based on previous findings, children living in single parent-households were expected to be more exposed to traumatizing events leading to PTSD than children living with both their parents [12]. Considering the life circumstances in India, it was also expected that Indian adolescents in general are more exposed to possible traumatizing events than European adolescents.

\section{METHODS}

\subsection{Subjects}

The data in the present study derives from responses of 411 Indian 9th grade students. The students were from 13 to 16 years old $($ mean $=14.15, \mathrm{SD}=0.47)$. The gender distribution was 192 females (46.7\%) and 219 males $(53.3 \%)$. The sample of Indian adolescents in this study was from the city of Pune in the state of Maharashtra. Because of limited resources such as time and finances, the study focused solely on subjects from Pune city only, and furthermore only on students from private schools. Five schools in the city were chosen and asked to participate but only two decided to enroll in the study. Both 
schools were private schools with students primarily from a middle and upper class background. Each of the 8 participating classes consisted of 50 to 60 students ( $\mathrm{M}=$ 55) and an average of 4 students were missing on the day the study was conducted.

\subsection{Procedures}

Prior to the study, the questionnaire was introduced to the headmasters and the boards of the schools by a letter explaining the aims of the study. The study was then introduced to the students verbally and by letter. The students filled in the questionnaire in the classroom, supervised by the first author in co-operation with two Hindispeaking Indian psychology students, who explained the purpose of the study, the principles of confidentiality and practicalities in answering the questionnaire. The students were informed that their answers were anonymous; that it was voluntary to participate and they were asked to answer as truthfully as possible, in spite of the somewhat uncomfortable subject. All students present wished to participate in the study.

\subsection{Measures}

The first part of the questionnaire contained questions about demographic variables such as gender, age and living arrangements. The last part of the questionnaire contained a list of 20 potentially traumatizing events (PTEs; see Table 1) where the students were asked to point out which of these they had been exposed to (direct exposure), and which they had witnessed or heard someone being exposed to (indirect exposure). This list of events was selected on the basis of prior research and clinical experience covering both events that meet the DSM IV A1 Criterion and also some potentially negative life events such as pregnancy/abortion, divorce, being bullied, and absence of a parent. These negative life events were included because it has been shown that not only experiences that meet Criterion A1, but also other intense negative experiences in the family environment can be associated with traumatic responses in adolescents [12]. Psychometric data is not yet available for the negative life event measures but data from multiple studies supports that the events included in the 20 item questionnaire are frequently experienced by youths across nations and cultures and that they are potentially traumatizing [12-17].

The students were asked to pick out the event that they regarded as being the most stressful. The Harvard Trauma Questionnaire Part IV (HTQ) [26] was used to determine the level of PTSD at the time after this event. The

Table 1. Potential trauma events and life events according to exposure and gender.

\begin{tabular}{|c|c|c|c|c|c|c|c|}
\hline & \multirow{3}{*}{ Event } & \multicolumn{3}{|c|}{ Direct exposure in percentage } & \multicolumn{3}{|c|}{ Indirect exposure in percentage } \\
\hline & & Females & Males & $\mathrm{All}^{*}$ & Females & Males & $\mathrm{All}^{*}$ \\
\hline & & $(\mathrm{n}=192)$ & $(\mathrm{n}=219)$ & $(=411)$ & $(\mathrm{n}=192)$ & $(\mathrm{n}=219)$ & $(=411)$ \\
\hline 1 & Traffic accident & 26.0 & 50.7 & $39.2^{3}$ & 47.4 & 55.7 & 51.8 \\
\hline 2 & Other serious accidents & 9.9 & 23.3 & $17.0^{3}$ & 25.0 & 38.4 & $32.1^{1}$ \\
\hline 3 & Physical assault & 2.6 & 12.3 & $7.8^{3}$ & 6.8 & 14.2 & $10.7^{1}$ \\
\hline 4 & Rape & 0.0 & 2.3 & $1.2^{1}$ & 1.0 & 5.9 & $3.6^{1}$ \\
\hline 5 & Witnessed other people injured or killed & 11.5 & 24.7 & $18.5^{2}$ & 17.7 & 24.7 & 21.4 \\
\hline 6 & Came close to being injured or killed & 16.7 & 19.6 & 18.2 & 12.0 & 17.8 & 15.1 \\
\hline 7 & Threats of violence & 4.7 & 15.5 & $10.5^{3}$ & 7.8 & 16.0 & $12.2^{1}$ \\
\hline 8 & Near-drowning & 3.1 & 13.2 & $8.5^{3}$ & 5.2 & 11.0 & $8.3^{1}$ \\
\hline 9 & Attempted suicide & 1.0 & 3.7 & 2.4 & 7.8 & 12.3 & 10.2 \\
\hline 10 & Robbery/theft & 5.7 & 15.5 & $10.9^{2}$ & 16.7 & 31.5 & $24.6^{3}$ \\
\hline 11 & Pregnancy/abortion & 2.1 & 4.6 & 3.4 & 18.8 & 19.6 & 19.2 \\
\hline 12 & Serious illness & 21.9 & 32.4 & $27,5^{1}$ & 35.9 & 38.4 & 37.2 \\
\hline 13 & Death of someone close & 40.6 & 42.0 & 41.4 & 43.2 & 42.5 & 42.8 \\
\hline 14 & Divorce & 1.0 & 3.7 & 2.4 & 4.7 & 8.7 & 6.8 \\
\hline 15 & Sexual abuse & 1.0 & 4.1 & 2.7 & 1.6 & 5.9 & $3.9^{1}$ \\
\hline 16 & Physical abuse & 4.7 & 7.3 & 6.1 & 4.2 & 10.5 & $7.5^{1}$ \\
\hline 17 & Severe childhood neglect & 3.1 & 5.5 & 4.4 & 7.3 & 12.3 & 10.0 \\
\hline 18 & Bullying & 7.8 & 15.1 & $11.7^{1}$ & 9.4 & 13.7 & 11.7 \\
\hline 19 & Absence of a parent & 7.8 & 8.7 & 8.3 & 12.0 & 14.2 & 13.1 \\
\hline 20 & Other events & 4.7 & 4.6 & 4.6 & 0.0 & 1.4 & 0.7 \\
\hline
\end{tabular}


HTQ consisted of 31 items, of which the first 17 correspond to the PTSD-symptoms in the DSM-IV. The items were scored on a 4-point Likert scale $(1=$ not at all, $4=$ extremely). Since diagnostic interviews were notperformed the PTSD scores were not fully diagnosed PTSD: Intrusion (criteria B), Avoidance (criteria C) and Hypervigilance (criteria $\mathrm{D}$ ). To meet the diagnostic criteria for PTSD it is necessary to have symptoms from all three symptom clusters; at least one symptom from the Intrusion symptom cluster, 3 symptoms or more from the Avoidance symptom cluster and 2 symptoms or more from the Hypervigilance symptom cluster. Good validity and reliability on HTQ has been reported cross-culturally $[26,27]$ in very culturally diverse countries, although it seems that certain items may carry different meanings across cultures [28]. The internal consistency of the scale was found to be good in the present study: Cronbach's alpha $=0.91$ for the total HTQ scale.

\section{RESULTS}

$78.1 \%$ of the students reported having directly experienced or witnessed at least one potentially traumatizing event (females $=70 \%$, males $=85 \%$ ). The most common events recorded were death of someone close $(41.4 \%)$, traffic accidents (39.2\%), serious illness $(27.5 \%)$, witnessing the injury or killing of others $(18.5 \%)$ and coming close to being injured or killed (18.2\%, see Table 1).

The mean number of direct events experienced per respondent was $2.5(\mathrm{SD}=2.46)$. The average number of indirect events per respondent was $3.4(\mathrm{SD}=3.13)$. On average, males experienced 3.1 events directly and females 1.8; the difference reached significance in a oneway ANOVA (F1, $409=32.0 ; \mathrm{p}<0.0005)$. There was also a significant difference between males and females in the number of indirect events experienced (Males $=$ 3.8 , Females $=2.8(\mathrm{~F} 1,409=10.3, \mathrm{p}<0.0005))$. In general, males reported more direct exposure to all potentially traumatizing events compared to females. This was especially the case for traffic accidents, other serious accidents, physical assault, witnessing the injury or killing of others, and receiving threats of violence.

410 students stated with whom they live: 395 (96.1\%) lived with both parents, 12 (2.9\%) lived with one parent and $3(0.7 \%)$ lived with other family members. Adolescents coming from a single-parent household reported more direct exposure to possible traumatizing events (3.5 events versus 2.4 events $\left.\left(\chi^{2}=32.3, \mathrm{p}<0.0005\right)\right)$ and had an increased risk of PTSD $\left(\chi^{2}=5.06, p<0.03\right)$ compared to adolescents living with both parents. The same difference was not found for indirect exposure.

In Table 2, the odds ratios for each type of event are provided. Threats of violence, attempted suicide, physical abuse, severe childhood neglect and humiliation or persecution were associated with OR's $>2.0$, while phy-
Table 2. Odds ratios and $95 \%$ CI intervals for the potential trauma events and life events direct exposure in predicting a PTSD-like state 95\% CI for exp (B).

\begin{tabular}{|c|c|c|c|c|}
\hline & Event & OR & Lower & Upper \\
\hline 1 & Traffic accident & 0.94 & 0.41 & 2.14 \\
\hline 2 & Other serious accidents & 1.68 & 0.67 & 4.20 \\
\hline 3 & Physical assault & 0.24 & 0.04 & 1.52 \\
\hline 4 & Rape & 0.27 & 0.01 & 11.37 \\
\hline 5 & $\begin{array}{c}\text { Witnessed other } \\
\text { people injured or killed }\end{array}$ & 1.77 & 0.73 & 4.32 \\
\hline 6 & $\begin{array}{c}\text { Came close to } \\
\text { being injured or killed }\end{array}$ & 0.89 & 0.33 & 2.41 \\
\hline 7 & Threats of violence & 2.12 & 0.66 & 6.78 \\
\hline 8 & Near-drowning & 0.61 & 0.15 & 2.45 \\
\hline 9 & Attempted suicide & 4.66 & 0.44 & 49.08 \\
\hline 10 & Robbery/theft & 1.40 & 0.46 & 4.31 \\
\hline 11 & Pregnancy/abortion & 0.68 & 0.10 & 4.79 \\
\hline 12 & Serious illness & 0.70 & .27 & 1.82 \\
\hline 13 & Death of someone close & 1.01 & 0.45 & 2.26 \\
\hline 14 & Divorce & 0.54 & 0.04 & 7.59 \\
\hline 15 & Sexual abuse & 0.81 & 0.07 & 9.42 \\
\hline 16 & Physical abuse & 2.18 & 0.57 & 8.33 \\
\hline 17 & $\begin{array}{c}\text { Severe } \\
\text { childhood neglect }\end{array}$ & $8.67^{*}$ & 1.96 & 38.39 \\
\hline 18 & $\begin{array}{c}\text { Humiliation or } \\
\text { persecution (bullying) }\end{array}$ & $3.46^{*}$ & 1.31 & 9.11 \\
\hline 19 & Absence of a parent & 1.57 & 0.48 & 5.15 \\
\hline 20 & Miscellaneous & $4.40^{*}$ & 1.25 & 15.50 \\
\hline
\end{tabular}

sical assault and rape had OR's $<0.50 .10 \%$ of the sample fulfilled the criteria for PTSD, and there was no significant gender difference (females $=8.9 \%$, males $=$ $10.5 \%)$.

\section{DISCUSSION}

Despite cultural differences between India and European countries, this study revealed similar exposure rates to similar studies conducted in Europe. Of the students, $78.1 \%$ reported direct exposure to at least one PTE $(70 \%$ of females and $85 \%$ of males). The prevalence of PTSD was also very similar to previous findings among adolescents from other countries, with $10 \%$ of the Indian students fulfilling the diagnostic criteria for PTSD.

No gender difference was found in the prevalence of PTSD, with $8.9 \%$ females and $10.5 \%$ males fulfilling the diagnostic criteria for PTSD. This contradicts most other studies conducted on PTSD in adult as well as adolescent samples. Previous studies using the same methodology 
as the present study all find that adolescent females fulfill the criteria for PTSD twice as often (or more) as males $[12-15,19]$. Large national probability studies conducted earlier also find these gender differences [20,29].

The present data suggest that the Indian boys are more directly exposed than girls to all PTEs. The general tendency of boys being more exposed than girls has also been found in a similar Kenyan study [17] and may be explained by certain specific cultural norms and restrictions. It may be an expression of either a cultural heightened focus on protection of girls in these countries, a lessened focus on protection of boys, or a combination of both. In India, girls are attended and monitored closely, and parents are often rather strict in their regulation of girls' behavior as their "purity" till marriage is very important [30,31]. Boys, on the other hand, are more free to do what they like, which explains the greater exposure to potentially traumatizing events. This freedom might also impose greater pressure and responsibility on the boys, which could be an explanation for the greater traumatizing effect of distressing events on boys.

Twice as many boys than girls reported direct exposure to pregnancy/abortion which seems quite peculiar. The most obvious explanation is, that the boys reported pregnancies where they were directly involved. When a boy in India impregnates a girl, it is often forced on him to marry the girl and to take full responsibility of his actions, or alternatively to raise money for an early abortion. Thus, because there are a lot of negative circumstances automatically related to getting a girl pregnant, especially for a young boy, it may be reported as direct exposure to a PTE. In a Western frame of mind, we would expect that issues such as rape and sexual abuse would be more prevalent in females than males. Even so, the present results are comparable to a similar Kenyan study where the males also reported higher exposure to pregnancy/abortion, rape and sexual abuse than the females [17]. Some boys could have misunderstood the purpose of the question and may have reported their own direct experience of sexually abusing, impregnating or raping another person. An additional explanation of the higher reports of sexual abuse and rape in the Indian and Kenyan boys than girls, may be found in that the majority of people in India and Kenya regard sex before marriage as being wrong and a girl in these countries may be rejected (by the family or society) or regarded of less value if she has had sexual relations before she is married whether it is her own fault or not [30-32]. The same, however, is not the case for the boys. Therefore, girls may be more reluctant to report sexually related issues such as abuse, rape or pregnancy/abortion than males in these countries.

The prevalence of direct exposure in the present study was comparable to previous European studies (present study $=2.5$ events per respondent, previous studies $=1.9$ 3.1 events per respondent). This can be considered surprising in that life circumstances in India includes poverty, terror attacks, riots, and natural disasters. Hence, the exposure to traumatizing events was expected to be higher. The most likely explanation is that the subjects in the present study have been brought up in a somewhat protected environment and have therefore not been exposed to PTE's that are otherwise frequently occurring in India. Another possible explanation is the difference in cultural definitions of specific events and what is considered traumatizing. In India the use of physical punishment is illegal, but is nevertheless still accepted and used in most schools, and is therefore not necessarily regarded as violence in India as opposed to many Western European countries. Likewise, Indians may be used to seeing for example traffic accidents, starving children in the streets, riots, and terror attacks. Hence, they might be subjects to a form of habituation and perceive the events as less distressing and therefore report less events as traumatizing [16,33-36]. Finally, one must also consider the importance of religion. Religious beliefs have been found to be a mediating factor in the development of PTSD [37], this could be explained from a cognitive view, in that a "sense of coherence" and the ability to see the traumatizing event as meaningful (due to one's karma or Allah's will) makes it easier to adapt it to an existing schemata [38]. This might be the case for many Indians since religion plays a central role in the Indian society.

As predicted, living in a single-parent household meant increased risk of developing PTSD. According to [12], a two-parent household may provide more sufficient parental supervision and better socioeconomic opportunities and this seems to apply for India as well. In contrast to earlier studies, the odds ratios for developing PTSD after physical assault and rape were very low $(<0.5)$. However, the exposure to these specific events was low in the sample and the estimates may therefore be subject to uncertainty.

The sample is not representative and it is therefore not possible to conclude anything general about Indian youth based on the present study. However, this study is an important contribution to the PTSD literature, since it is performed in an Indian setting in a sub-community which is rarely studied. It is an interesting find that Indian students from private schools in Pune city report experiences and a prevalence of traumatization that are similar to studies from multiple European countries. The present data is not in accordance with prior reports of e.g. sexual abuse among Indian children and youths, and it is not in accordance with our expectations of a higher prevalence of PTEs in India than found in European countries. Whereas Kacker et al. [21] found extremely high exposure to physical and sexual abuse in the report on child 
abuse in India, this study has found a degree of exposure much more in line with similar studies conducted in Europe [12-15].

In this study, $6.1 \%$ report physical abuse (Kacker $\approx$ $66 \%$ ) while $2.7 \%$ report sexual abuse (Kacker $\approx 53 \%$ ). The sample in Kacker et al.'s study represents children and adolescents from very different socio-economic situations, whereas the sample in the present study is drawn from two upper middle class schools in one city. Future studies about protective factors in private schools vs public schools such as financial support, parental relations, socio economic status, social support etc. could thus provide valuable knowledge on prevention of experiences of PTE's and development of PTSD in Indian adolescents.

\section{CONCLUSION}

In conclusion, the present sample of Indian adolescents are as exposed to traumatizing events, as adolescents in European studies. Also, they are just as likely to develop symptoms of PTSD after potentially traumatizing events. Males are exposed to more direct and indirect traumatic events than females which is in line with earlier research on the topic. A notable difference in this study compared to similar studies in Western Europe is the absence of gender differences in PTSD development. Whereas earlier studies on the subject reveal a rate of PTSD around twice as high for females as for males, we found no such difference. Another curious find is that boys report sexual abuse, rape and pregnancy/abortion more often than girls. One might speculate if living conditions for girls in India are significantly more protective or otherwise preventive of PTSD development, and if the expectations and pressure on the boys are higher. Furthermore certain cultural aspects may have affected the way the students responses and it is a possibility that Indian girls may be more reluctant to report sexually related issues than boys. In line with earlier research, we found that single parenthood increases the risk of PTSD after experiencing a traumatizing event. Finally, it is seen how some traumatizing events are associated with greater risk for PTSD than others; the ones with highest risk being: Threats of violence, attempted suicide, physical abuse, severe childhood neglect, and humiliation or persecution. The study is not representative but provides valuable knowledge about Indian students from a certain socio economic class. Among others the present study can be used as a base for future studies on risk and protective factors associated with adolescents' experiences of PTEs and development of PTSD in India.

\section{Limitations}

This study has several limitations. First of all, the sample is not representative in that it is local and covers a certain socio-economic class. Future studies that cover adoles- cents from other areas and other socio-economic classes are necessary to conclude anything general about Indian youth regarding experiences of PTEs and PTSD. The study relied on self-reports which may have produced some bias. The questionnaires were anonymous, but the practical conditions in the classroom might have compromised the feeling of actual anonymity (e.g., the students were sitting very close to one another and some of their teachers were present). Even though English is the official language in Maharashtra along with Hindi and Marathi, some language difficulties were present (for example a word like "nightmare" was unknown to some students). Some cultural bias may also have affected the results. The event questionnaire has not been validated and is originally constructed to reflect a European sample. Questions concerning e.g. natural disasters, terror, religious riots, and caste discrimination were not included and might very well have been relevant. The exclusion of culturally defined stressors might compromise the accuracy of the estimated PTSD occurrence. All the same, this study is one of the first to look at a broad range of potentially traumatizing events and lifetime PTSD prevalence in a large sample of adolescents in India. As such, it contributes valuable information to a field that is only sparsely investigated.

\section{REFERENCES}

[1] Breslau, N., Kessler, R.C., Chilcoat, H.D., Schultz, L.R., Davis, G.C. and Andreski, P. (1998) Trauma and posttraumatic stress disorder in the community: The 1996 Detroit area survey of trauma. Archives of General Psychiatry, 55, 626-631. doi:10.1001/archpsyc.55.7.626

[2] Caffo, E., Forresi, B. and Lievers, L.S. (2005) Impact, psychological sequelae and management of trauma effecting children and adolescents. Current Opinion in Psychiatry, 18, 422-428. doi:10.1097/01.yco.0000172062.01520.ac

[3] Dyregrov, A. and Yule, W. (2006) A review of PTSD in children. Child and Adolescent Mental Health, 11, 176184. doi:10.1111/j.1475-3588.2005.00384.x

[4] Schäfer, I., Barkmann, C., Riedesser, P. and SchulteMarkwort, M. (2006) Posttraumatic syndromes in children and adolescents after road traffic accidents-A prospective cohort study. Psychopathology, 39, 159-164. doi:10.1159/000092676

[5] Meiser-Stedman, R., Yule, W., Smith, P., Glucksman, E. and Dalgleish, T. (2007) Acute stress disorder and posttraumatic stress disorder in children and adolescents involved in assaults and motor vehicle accidents. American Journal of Psychiatry, 162, 1381-1383. doi:10.1176/appi.ajp.162.7.1381

[6] Edgardh, K. and Ormstad, K. (2000) Prevalence and characteristics of sexual abuse in a national sample of Swedish seventeen-year-old boys and girls. Acta Pediatrica, 88, 310-319. doi:10.1111/j.1651-2227.2000.tb01333.x 
[7] La Greca, A.M. and Prinstein, M.J. (2002) Hurricanes and earthquakes. In: La Greca, A.M., Silverman, W.K., Vernberg, E.M. and Roberts, M.C., Eds., Helping Children Cope with Disasters and Terrorism, American Psychological Association, Washington DC, 107-138. doi:10.1037/10454-005

[8] Thabet, A.A., Tawahina, A.A., El Sarraj, E. and Vostanis, P. (2008) Exposure to war trauma and PTSD among parents and children in the Gaza strip. European Child \& Adolescent Psychiatry, 17, 191-199. doi:10.1007/s00787-007-0653-9

[9] Giaconia, R.M., Reinherz, H.Z., Silverman, A.B., Pakiz, B., Frost, A.K. and Cohen, E. (1995) Traumas and posttraumatic stress disorder in a community population of older adolescents. Journal of the American Academy of Child \& Adolescent Psychiatry, 34, 1369-1380. doi:10.1097/00004583-199510000-00023

[10] Joseph, S., Mynard, H. and Mayhall, M. (2000) Lifeevents and post-traumatic stress in a sample of English adolescents. Journal of Community \& Applied Social Psychology, 10, 475-482.

doi:10.1002/1099-1298(200011/12)10:6<475::AID-CAS P578>3.0.CO;2-F

[11] Costello, E.J., Erkanli, A., Fairbank, J.A. and Angold, A. (2002) The prevalence of potentially traumatic events in childhood and adolescence. Journal of Traumatic Stress, 15, 99-112. doi:10.1023/A:1014851823163

[12] Elklit, A. (2002) Victimization and PTSD in a Danish national youth probability sample. Journal of the American Academy of Child \& Adolescent Psychiatry, 41, 174-181. doi:10.1097/00004583-200202000-00011

[13] Bödvarsdóttir, I. and Elklit, A. (2007) Victimization and PTSD in an Icelandic youth probability sample. $B M C$ Psychiatry, 7, 51. doi:10.1186/1471-244X-7-51

[14] Domainskaite-Gota, V., Elklit, A. and Christiansen, D. (2009) Victimization and PTSD in a Lithuanian national youth probability sample. Nordic Psychology, 61, 66-81. doi:10.1027/1901-2276.61.3.66

[15] Petersen, T., Olesen, J.G. and Elklit, A. (2010) Victimization and PTSD in a Faroese youth total population sample. Scandinavian Journal of Psychology, 51, 56-62. doi:10.1111/j.1467-9450.2009.00728.x

[16] Rhiger, M., Elklit, A. and Lasgaard, M. (2008) Trauma in an Israeli youth sample: An investigation of the prevalence and psychological impact of exposure to traumatic experiences. Nordic Psychology, 60, 101-113. doi:10.1027/1901-2276.60.2.101

[17] Karsberg, S. and Elklit, A. (2012) Victimization and PTSD in a rural Kenyan youth sample. Clinical Practice and Epidemiology in Mental Health, in Press.

[18] Meltzer, H., Gatward, R., Goodman, R. and Ford, T. (2000) Mental health of children and adolescents in Great Britain. The Stationery Office, London.

[19] Ditlevsen, D.N. and Elklit, A. (2010) The combined effect of gender and age on post-traumatic stress disorder: Do men and women show differences in the lifespan distribution of the disorder? Annals of general psychiatry, 9, 32. doi:10.1186/1744-859X-9-32
[20] Kessler, R.C., Sonnega, A., Bromet, E. and Hughes, M. (1995) Posttraumatic stress disorder in the national comorbidity survey. Archives of General Psychiatry, 52, 1048-1060. doi:10.1001/archpsyc.1995.03950240066012

[21] Kacker, L., Varadan, S. and Kumar, P. (2007) Study on child abuse: India 2007. Ministry of Women and Child Development, Government of India.

[22] Kumar, M. (2007) A journey into the bleeding city: Following the footprints of the rubble of riot and violence of earthquake in Gujarat, India. Psychology and Developing Societies, 19, 1-36. doi:10.1177/097133360701900101

[23] Seethalakshmi, R., Dhavale, H., Gawande, S. and Dewan, M. (2006) Phychiatric morbidity following motor vehicle crashes: A pilot study from India. Journal of Psychiatric Practice, 12, 415-418. doi:10.1097/00131746-200611000-00012

[24] Varma, D., Chandra, P., Thomas, T. and Carey, M. (2007) Intimate partner violence and sexual coercion among pregnant women in India: Relationship with depression and post-traumatic stress disorder. Journal of Affective Disorders, 102, 227-235. doi:10.1016/j.jad.2006.09.026

[25] Kar, N., Mohaprata, P., Nayak, K., Pattanaik, P., Swain, S. and Kar, H. (2007) Post-traumatic stress disorder in children and adolescents one year after a super-cyclone in Orissa, India: Exploring cross-cultural validity and vulnerable factors. BMC Psychiatry, 7, 8. doi:10.1186/1471-244X-7-8

[26] Mollica, R.F., Caspi-Yavin, Y., Billini, P., Truong, T., Tor, S. and Lavelle, J. (1992) The Harvard Trauma Questionnaire: Validating a cross-cultural instrument for measuring torture, trauma, and post-traumatic stress disorder in Indochinese refugees. Journal of Nervous and Mental Disease, 180, 111-116. doi:10.1097/00005053-199202000-00008

[27] Kleijn, W.C., Hovens, J.E. and Rodenburg, J.J. (2001) Posttraumatic stress symptoms in refugees: Assessments with the Harvard Trauma Questionnaire and the Hopkins Symptom Checklist-25 in different languages. Psychological Reports, 88, 527-532. doi:10.2466/pr0.2001.88.2.527

[28] Renner, W., Salem, I. and Ottomeyer, K. (2006) Crosscultural validation of psychometric measures of trauma in groups of asylum seekers from Chechnya, Afghanistan and West Africa. Journal of Social Beahvior and Personality, 35, 1101-1114. doi:10.2224/sbp.2006.34.9.1101

[29] Breslau, N., Davis, G.C., Andreski, P. and Peterson, E.L. (1997) Sex differences in posttraumatic stress disorder. Archives of General Psychiatry, 54, 1044-1048. doi:10.1001/archpsyc.1997.01830230082012

[30] Young, J. (2006) Culture, masculinity, and psychological well-being in Punjab, India. Sex Roles, 55, 715-724. doi:10.1007/s11199-006-9126-8

[31] Mahalingam, R. (2007) Beliefs about chastity, machismo, and caste identity: A cultural psychology of gender. Sex Roles, 56, 239-249. doi:10.1007/s11199-006-9168-y

[32] Pattman, R. and Chege, F. (2003) Dear diary I saw an angel, she looked like heaven on earth: Sex talk and sex education. African Journal of AIDS Research, 2, 103-112. 


$$
\text { doi:10.2989/16085906.2003.9626565 }
$$

[33] Kalayjian, A., Kanazi, R.L., Aberson, C. and Feygin, L. (2002) A cross-cultural study of psychosocial and spiritual impact of natural disaster. International Journal of Group Tension, 31, 175-186. doi:10.1023/A:1015260717000

[34] Solomon, Z. and Laufer, A. (2004) In the shadow of terror: Changes in world assumptions in Israeli youth. Journal of Aggression, Maltreatment \& Trauma, 9, 353-364. doi:10.1300/J146v09n03 06

[35] Levinson, S., Shulman, S., Fernbuch, S. and Erez, T. (1994) Emotional fear reactions and their personality and environmental correlates in children and young adolescents after the Gulf War. Psychologia: Israel Journal of
Psychology, 4, 158-169.

[36] Rachman, S. (1978) Fear and courage. W. H. Freeman, San Francisco.

[37] Sachs, E., Rosenfeld, B., Lhewa, D., Rasmussen, A. and Keller, A. (2008) Entering exile. Trauma, mental health, and coping among Tibetan refugees arriving in Dharamsala, India. Journal of Traumatic Stress, 21, 199-208. doi: $10.1002 /$ jts. 20324

[38] Frommberger, U., Stieglitz, R.D., Straub, S., Nyberg, E., Schlickewei, W., Kuner, E. and Berger, M. (1999) The concept of sense of coherence and the development of posttrauamtic stress disorder in traffic accident victims. Journal of Psychosomatic Research, 44, 343-348. doi:10.1016/S0022-3999(98)00117-2 